\title{
Clinical improvement of nursing intervention in swallowing dysfunction of elderly stroke patients.
}

\author{
Rui Zhang', Xin-Mei Ju ${ }^{2 *}$ \\ ${ }^{1}$ Medical Examination Center, Sino-Singapore Eco-City Hospital of Tianjin Medical University, Tianjin, PR China \\ ${ }^{2}$ Fundamental Nursing Teaching Research Office, International Nursing School of Hainan Medical University, Haikou, \\ Hainan, PR China
}

\begin{abstract}
Objective: This study aims to discuss clinical improvement of nursing intervention in swallowing dysfunction of elderly stroke patients.

Methods: A total of 120 elderly stroke patients with swallowing dysfunction admitted in our hospital from February 2016 to September 2017 were chosen and randomly divided into control $(\mathrm{n}=60)$ and intervention groups $(n=60)$. The control group was provided with conventional nursing service, and the intervention group was provided with nursing intervention. Improvements of swallowing dysfunction, living quality, pulmonary infection, and nursing satisfaction were compared between the two groups.

Results: The total efficiencies in improving swallowing dysfunction are $96.67 \%$ and $83.33 \%$ for the intervention and control groups, respectively, and the difference was statistically significant $(\mathbf{P}<0.05)$. The scores of physical functions, psychological functions, social functions, and material life are higher in the intervention group than those in the control group $(P<0.05)$. The pulmonary infection rate in the intervention group $(\mathbf{1 . 6 7 \%})$ is also lower than that in the control group $(\mathbf{1 1 . 6 7 \%}, \mathbf{P}<\mathbf{0 . 0 5})$. Nursing satisfaction was significantly different between the two groups $(P<0.05)$. The scores of nursing satisfaction are $\mathbf{9 8 . 3 3 \%}$ and $\mathbf{8 8 . 3 3 \%}$ in the control and intervention groups, respectively.

Conclusions: Nursing intervention exerts a significant clinical effect on improving swallowing dysfunction of elderly stroke patients. Such intervention can also improve the living quality and nursing satisfaction of the patients and reduce pulmonary infection rate. Hence, nursing intervention is worthy of clinical research and promotion.
\end{abstract}

Keywords: Elderly, Stroke, Nursing invention, Swallowing dysfunction.

Accepted on December 11, 2017

\section{Introduction}

Swallowing dysfunction is a common complication of stroke and has a morbidity range of $37 \%$ and $78 \%$. This condition also causes aspiration pneumonia, asphyxia, mistake aspiration and swallowing and death [1]. The morbidity of stroke increases gradually with continuous changes in the living habits of people particularly in the aging population; after stroke, the occurrence of swallowing functions increases $[2,3]$. Therefore, effectively relieving swallowing dysfunction has become a research key in clinical nursing [4]. In this study, 10 elderly stroke patients with swallowing dysfunction admitted in our hospital from February 2016 to September 2017 were chosen as participants to discuss the effects of nursing intervention.

\section{Information and Methods}

\section{General information}

A total of 120 elderly stroke patients with swallowing dysfunction admitted in our hospital from February 2016 to September 2017 were chosen and randomly divided into control $(n=60)$ and intervention groups $(n=60)$. The control group consisted of 27 females and 33 males aged 61 to $82 \mathrm{y}$ in average $(70.57 \pm 7.36 \mathrm{y})$. The intervention group consisted of 28 females and 32 males aged 60 to 82 years in average $(70.25$ \pm 7.38 y). Statistical analysis of data was carried out by SPSS 18.0 and showed no statistical difference between the two groups $(\mathrm{P}>0.05)$. All respondents and their family members were informed about the research objective and volunteered in this study upon signing an informed consent form. This study agrees with the requirements of the Ethics Committee of our hospital. 


\section{Methods}

The control group was provided with a conventional nursing service that strictly conforms to the doctor's advice. The intervention group was given with nursing intervention.

Psychological intervention: The nursing staff initiates communication with the patients, evaluates their psychological state, encourages and comforts them according to their actual situation, and lets them participate into the treatment and nursing service positively [5]. The nursing staff also communicates with the family members of the patients positively, guides them to encourage and support the patients, and gives them the warm love of family, thus helping the patients to have a stable and optimistic attitude. Excellent nursing effect was achieved through these interventions.

Health education: The nursing staff introduces knowledge about swallowing dysfunction and possible untoward effects on the patients through videos and images, thus enhancing their enhancing their knowledge and encouraging them to cooperate in their therapy and nursing care [6].

Rehabilitation exercises: (1) pronunciation training: the nursing staff makes some character and word cards and guides the pronunciation training of the patients. The pronunciation training should start from simple characters, and the pronunciation difficulty can be increased gradually according to the actual situations of the patients [7]. The pronunciation training should be performed according to the tolerance of the patients at appropriate time. (2) Lingualis and masticatory muscle training: the nursing staff guides the patients to make appropriate lingualis and masticatory muscle training, such as shrinking the tongue, uplifting the tongue, and resisting the posterior hard palate by the tongue. (3) Mouth-opening training: the nursing staff guides the patients to stick their tongue, turn it, and train for other masticatory functions. (4) Cheek-and-throat muscle training: the nursing staff guides the patients to perform exercises of sucking, opening and closing mouths, blowing and cheek bulging, stimulating soft palate and tongue root by cold cotton swabs, and promoting swallowing of the patients. The swallowing time increases gradually. (5) Ingestion training: the nursing staff guides the patients to ingest food according to their positions. If the patients can lie on the back, then their body should lie on the back. If the patients can sit up, then they are asked to make heads anteflexion to ensure smooth ingestion.

Diet intervention: appropriate foods should be chosen according to specific conditions of the patients. In general, the selected foods are easy to digest and ruminate and include thick soup and food paste. Moreover, the patients are asked not to take hard foods, which are difficult to digest. If the patients are in comatose state, then spoon meat can be given.

\section{Observation indices}

Improvement of swallowing dysfunction, living quality, pulmonary infection, and nursing satisfaction were compared between the two groups.
Swallowing dysfunction was evaluated using the following standards: cured: patients drink $30 \mathrm{ml}$ of water once in $5 \mathrm{~s}$ without bucking; significant improvement: patients drink $30 \mathrm{ml}$ of water once in $5 \mathrm{~s}$ with bucking; improvement: patients drink $30 \mathrm{ml}$ of water twice in $5 \mathrm{~s}$ accompanied with bucking; no improvement: patients drink $30 \mathrm{ml}$ of water in $10 \mathrm{~s}$ accompanied with several bucking. The total efficiency is the sum of cure, significant improvement, and improvement scores.

Living quality was evaluated using the standard: living quality of the patients was evaluated by the comprehensive assessment questionnaire of living quality (GQOL-74), including physical functions, psychological functions, social functions, and material life. The complete score of each item was 100. High scores indicate improved living quality.

Nursing satisfaction was assessed by a self-made questionnaire with the following scores (the complete score was 100 scores): very satisfying: $>85$; satisfying: $60-85$; and unsatisfying: $<60$. Nursing satisfaction is the sum of very satisfying and satisfying scores.

\section{Statistical analysis}

Statistical analysis on observation data of the two groups was carried out by SPSS 18.0. Enumeration data (e.g., total efficiency in improvement of swallowing dysfunction, pulmonary infection rate, and nursing satisfaction) were expressed by percentage and examined by chi-square test. Measurement data (e.g., physical function, psychological function, social function, and material life score) were expressed as $\overline{\mathrm{x}} \pm \mathrm{s}$ and examined by t-test. Values at $\mathrm{P}<0.05$ indicate statistically significant differences between the two groups.

\section{Results}

\section{Improvement of swallowing dysfunction}

The total efficiencies in improving swallowing dysfunction were $96.67 \%$ and $83.33 \%$ for the intervention and control groups, respectively, and the difference was statistically significant $(\mathrm{P}<0.05$, Table 1$)$.

\section{Living quality}

The intervention group achieved higher scores in physical functions, psychological functions, social functions, and material life than the control group $(\mathrm{P}<0.05$, Table 2$)$.

\section{Pulmonary infection}

The pulmonary infection rate in the intervention group $(1.67 \%)$ is lower than that in the control group $(11.67 \%)(\mathrm{P}<0.05$, Table 3). 


\section{Nursing satisfaction}

Nursing satisfaction significantly differed between the two groups $(\mathrm{P}<0.05)$, with scores of $98.33 \%$ and $88.33 \%$ for the intervention and control groups, respectively (Table 4).

Table 1. Comparison of improvements in swallowing dysfunction between the two groups (n, \%).

\begin{tabular}{llllr}
\hline Groups & Cured & Significant improvement & Improvement & No improvement \\
\hline Intervention & $37(61.67)$ & $12(20.00)$ & $9(15.00)$ & $2(3.33)$ \\
\hline Control & $18(30.00)$ & $20(33.33)$ & $12(20.00)$ & $58(96.67)$ \\
\hline$X^{2}$ & & & $50(83.33)$ & 5.9259 \\
\hline$P$ & & & 0.0149 \\
\hline
\end{tabular}

Table 2. Comparison of living quality between the two groups $(\bar{x} \pm s$, scores).

\begin{tabular}{lllll}
\hline Groups & $\begin{array}{l}\text { Physical } \\
\text { functions }\end{array}$ & $\begin{array}{l}\text { Psychologic } \\
\text { al functions }\end{array}$ & $\begin{array}{l}\text { Social } \\
\text { functions }\end{array}$ & Material life \\
\hline Intervention & $81.36 \pm 4.28$ & $60.36 \pm 5.48$ & $58.36 \pm 4.97$ & $77.93 \pm 5.46$ \\
\hline Control & $63.87 \pm 5.99$ & $41.97 \pm 6.62$ & $41.82 \pm 6.74$ & $61.28 \pm 6.21$ \\
\hline $\mathrm{t}$ & 18.4022 & 16.5755 & 15.2990 & 15.5969 \\
\hline $\mathrm{P}$ & 0.0000 & 0.0000 & 0.0000 & 0.0000 \\
\hline
\end{tabular}

Table 3. Comparison of pulmonary infection rate between the two groups $(n, \%)$.

\begin{tabular}{lll}
\hline Groups & Cases of pulmonary infection & Percentage \\
\hline Intervention $(n=60)$ & 1 & 1.67 \\
\hline Control $(n=60)$ & 7 & 11.67 \\
\hline$X^{2}$ & 4.8214 & \\
$P$ & 0.0281 & \\
\hline
\end{tabular}

Table 4. Comparison of nursing satisfaction between the two groups $(n, \%)$.

\begin{tabular}{lllll}
\hline Groups & $\begin{array}{l}\text { Very } \\
\text { satisfying }\end{array}$ & Satisfying & $\begin{array}{l}\text { Unsatisfyin } \\
\mathbf{g}\end{array}$ & $\begin{array}{l}\text { Satisfactio } \\
\mathbf{n}\end{array}$ \\
\hline $\begin{array}{l}\text { Intervention } \\
(\mathrm{n}=60)\end{array}$ & $37(61.67)$ & $22(36.67)$ & $1(1.67)$ & $59(98.33)$ \\
\hline Control $(\mathrm{n}=60)$ & $30(50.00)$ & $23(38.33)$ & $7(11.67)$ & $53(88.33)$ \\
\hline $\mathrm{X}^{2}$ & & & & 4.8214 \\
\hline $\mathrm{P}$ & & & & 0.0281 \\
\hline
\end{tabular}

\section{Discussion}

Swallowing dysfunction, a common complication in elderly stroke patients, causes pneumonia and dehydration and is a life threatening condition. In general, swallowing dysfunction refers to disability in swallowing, mouth and throat muscle dysfunction, and abnormal movement coordination related to swallowing activity [8]. For elderly stroke patients, physical functions deteriorate gradually, immunity declines continuously, and swallowing dysfunction occurs. These phenomena cause malnutrition and dehydration, thereby decreasing the living quality of patients [9,10]. Therefore, nursing services must be enhanced to relieve swallowing dysfunction of patients and improve their living quality.

This study reveals that the intervention group achieved higher total efficiency in improving swallowing dysfunction, physical function, psychological function, social function, material life, and nursing satisfaction than the control group $(\mathrm{P}<0.05)$. Moreover, the pulmonary infection rate in the intervention group is lower than that in the control group $(\mathrm{P}<0.05)$. Consistent with previous reports, the present findings indicate that the nursing intervention can relieve swallowing dysfunction, reduce pulmonary infection, and improve living quality and nursing satisfaction of patients. In the general nursing intervention, psychological intervention can effectively improve the unhealthy emotions of the patients and help them to set up confidence to therapy, thereby increasing their compliance in therapy and nursing. Health education can increase knowledge on their disease and further motivate subjective activity. Rehabilitation training can guide the patients in pronunciation, tongue activity, and throat muscle training, thus enabling them to improve mouth and throat functions, accelerate recovery of swallowing functions, and further improve their living quality. In addition, diet intervention ensures dietary nutrition equilibrium and facilitates rehabilitation of the patients.

\section{Conclusion}

Nursing intervention for elderly stroke patients has a significant clinical effect on improving their swallowing dysfunction. Moreover, the intervention can increase the living quality and nursing satisfaction of patients and reduce pulmonary infection rate. Nursing intervention is worthy of clinical research and promotion. 


\section{References}

1. Lo Coco D, Lopez G, Corrao S. Cognitive impairment and stroke in elderly patients. Vasc Health Risk Manag 2016; 12: $105-116$

2. Miloglu FD, Senol O, Kadiogli Y, Bilici M. Determination of retinol and beta-carotene after beta-carotene administration in patients with stomach cancer via HPLCDAD method in human plasma. Lat Am J Pharm 2017; 36: 740-749.

3. Altin C, Orhan ER. Designing wearable joystick and performance comparison of EMG classification methods for thumb finger gestures of joystick control. Biomed Res India 2017; 28: 4730-4736.

4. Yayan J. Effectiveness of alteplase in the very elderly after acute ischemic stroke. Clin Interv Aging 2013; 8: 963-974.

5. Shaikh AS, Bu F, Liu H, Geng C, Li P, Zhang R, Li W, Guo R. Comparison of novel LC-MS and EMIT methods for therapeutic monitoring of phenytoin in epilepsy patients and its clinical applications. Lat Am J Pharm 2017; 36: 783-788.

6. Buga AM, Ciobanu O, Badescu GM, Bogdan C, Weston R, Slevin M, Napoli MD, Popa-Wagner A. Up-regulation of serotonin receptor $2 \mathrm{~B}$ mRNA and protein in the periinfarcted area of aged rats and stroke patients. Oncotarget 2016; 7: 17415-17430.
7. Latchoumi TP, Parthiban L. Abnormality detection using weighed particle swarm optimization and smooth support vector machine. Biomed Res India 2017; 28: 4749-4751.

8. Turagam MK, Velagapudi P, Flaker GC. Stroke prevention in the elderly atrial fibrillation patient with comorbid conditions: focus on non-vitamin $\mathrm{K}$ antagonist oral anticoagulants. Clin Interv Aging 2015; 10: 1431-1444.

9. Yagi N, Nagami S, Lin M, Yabe T, Itoda M, Imai T, Oku Y. A noninvasive swallowing measurement system using a combination of respiratory flow, swallowing sound, and laryngeal motion. Med Biol Eng Comput 2017; 55: 1001-1017.

10. Knösel M, Klein S, Bleckmann A, Engelke W. Coordination of tongue activity during swallowing in mouth-breathing children. Dysphagia 2012; 27: 401-407.

\section{*Correspondence to}

Xin-Mei Ju

Fundamental Nursing Teaching Research Office

International Nursing School of Hainan Medical University

PR China 